\title{
SOFTWARE Project SCOPE VERIFICATION THROUGH DELIVERABLE-ORIENTED WORK BREAKDOWN STRUCTURE
}

\author{
Robert T. Hans \\ Tshwane University of Technology, Pretoria, South Africa \\ hansratut.ac.za
}

\begin{abstract}
Software project scope verification is a very important process in project scope management and it needs to be performed properly so as to avoid project rework and to promote better project scope control. Moreover, software scope verification is crucial in the process of delivering exactly what the customer requested and minimizing project scope changes. Well defined software scope eases the process of scope verification and contributes to project success. Furthermore, a deliverable-oriented WBS provides a road map to a well defined software scope of work. It is on the basis of this that this paper extends the use of deliverableoriented WBS to that of scope verification process. This paper argues that a deliverableoriented WBS is a tool for software scope verification
\end{abstract}

\section{KEYWORDS}

Software scope verification, scope definition, User requirements, WBS, Inspection

\section{INTRODUCTION}

A software project manager's success in managing a project is mainly based on how well he/she manages the project's triple constraint (project scope, cost, and time). User requirements must be collected and be well interpreted in the process of scope definition. The process of ensuring that a project scope is well defined and covers all user requirements aspects has proven to be a challenge for software project managers. Schwalbe (2011) agrees with this assertion and states that one of the critical and difficult aspects of project scope management has been project scope definition. It is important that a project team should have a well defined project scope right from the start of a project in order to:

- minimize project scope changes, scope creep and thereby aiding in scope control,

- ensure that products produced by the project meet user requirements and

- avoid unnecessary project rework.

The key question is how best can software project managers produce a project scope that meets all the abovementioned requirements? This is possible through the scope verification process. Schwalbe (2011:198) defines scope verification as a process that: 
'involves formal acceptance of the completed project scope by the stakeholders'

In order to do a thorough job in project scope verification, project team members and users should work closely together throughout the project life cycle. Moreover, Schwalbe (2011:198) states:

'The main tool for performing scope verification is inspection. The customer, sponsor, or user inspects the work after it is delivered'.

The field of software engineering has numerous research studies and books that have been written on the subject of scope verification. However, the researcher is not aware of any research study on using work breakdown structure (WBS) to verify software project scope. Therefore, this research paper seeks to close this theoretical void by suggesting the use of WBS as a tool for verifying software project scope. This aim is also strengthened by Rad (2001) who states that a WBS provides a road map to a well defined scope of work. It is on the basis of this that this paper extends the use of WBS to that of scope verification process.

\section{Literature ReVIEW}

\subsection{Introduction}

Software project success is generally measured using the triple constraint ('iron/golden' triangle), namely, cost goals, time goals and project performance in terms of project scope completion (Brewer \& Dittman, 2010). Therefore, an organization would want to have a software project scope finished within these constrains. Software companies are in constant search for tools and techniques that would assist project managers manage the triple constraint. Project scope management ensures that project stakeholders have the same understanding of what products the project will produce (Schwalbe, 2011). Furthermore, Schwalbe (2011) states that scope definition and scope verification are some of the processes used in project scope management.

\subsection{Project Scope Verification}

In broad terms, verification can be regarded as a 'process of determining whether a software development phase has been correctly carried out' (Schach, 1996). Scope verification is a process that is carried out under specification analysis phase. In this phase client's requirements are analyzed and interpreted in order to produce a specification document which will contain project scope of work. Project scope verification is an important process in ensuring that the project team delivers exactly what the customer requested (Brewer \& Dittman, 2010) and also in ensuring that project scope changes are minimal (Schwalbe, 2011). It is the process that formalizes the acceptance of the project scope. Various tools and techniques have been suggested for project scope verification process (Schwalbe, 2011; Schach, 1996) and these include:

- Inspection - the customer or user inspects the work after it is delivered.

- Prototyping - working replica of the planned system.

- Use case modeling - a tool used to model business events in order to gain better understanding of user requirements.

- Joint application design - a technique used to promote greater involvement of key project stakeholders in system development.

- Walkthrough - A document is carefully checked by a team of software professionals. 
Any of these tools and techniques may be applied in the process of project scope verification. In order for project scope verification to proceed smoothly, scope definition has to be done thoroughly. A well defined project scope is a pre-cursor for successful project scope control, project success and customer satisfaction. The next section discusses work breakdown structure which plays an important role in defining a project scope.

\subsection{Work Breakdown Structure (WBS)}

According to Schwalbe (2011:186) a work breakdown structure is:

'a deliverable-oriented grouping of the work involved in a project that defines the total scope of the project'.

In essence, a WBS is a decomposition of a large project into smaller manageable parts. The decomposition can proceed until the desired level of detail, lowest-level discrete deliverables, is reached (Fuller et al., 2008; Rad \& Cioffi, 2004). A WBS defines the total project scope (Schwalbe, 2011; Brewer \& Dittman, 2010; Malone, 2012). Therefore, a work breakdown structure is important to the success delivery of any software project (Fuller, Valacich and George, 2008) because it defines in detail the work necessary to accomplish a project's objectives. The successful delivery of the software project is in terms of cost and schedule (Zhao, 2006) performance - a WBS provides a foundation for better cost and schedule estimation. Chua and Godinot (2006) agree with this assertion and state that a WBS is widely regarded as powerful tool for better performance control. Furthermore, a typical WBS reflects user and/or system requirements (Fuller et al., 2008) as well as providing a basis for identifying resources and tasks for developing a project cost estimate. A well developed WBS also serves as a communication tool among stakeholders (U.S.A Government Accountability Office, 2006). Rad (2001) agrees with this assertion and states that a good WBS reduces the possibility of omitting key project elements. Software project managers use various tools and techniques in developing a WBS. The next section briefly discusses different approaches used in WBS development.

\subsection{Approaches in developing WBS}

The primary technique in creating a WBS is the decomposition process (Fuller et al., 2008; Schwalbe, 2011). A WBS can be presented in two forms, namely, hierarchical and tabular form (Fuller et al., 2008). According to Schwalbe (2011) there are various approaches that can be used in developing a WBS and these include:

- Using guidelines - organizational guidelines that are to be followed in developing work breakdown structures in the organization.

- An analogy approach - the use of a similar project's WBS in developing a WBS of the new project.

- The Top-down approach - one starts with largest items of the project and break them down into their subordinate items.

- The Bottom-up approach - one identifies specific related project tasks and organize them into summary activities (aggregate tasks).

- Mind mapping approach - one starts with a core idea and then link related ideas to the core idea. 
There is no single best approach in developing a WBS and therefore it is possible to use a combination of approaches in a WBS development (Schwalbe, 2011).

According to Cadle and Yeates (2008), in recent years experts have considered another approach to project planning and have suggested the use of product breakdown structure (PBS) or a deliverable-oriented WBS (Rad, 2001) in creating a WBS. The advantage of this approach is that the project's focus is on what is to be achieved rather than how, in other words the focus is on the ends instead of the means (Cadle and Yeates, 2008). The creation of a PBS uses the similar principles as in the creation of a WBS - progressively decomposing the project products into smaller products until a sensible, unitary product level is reached. The aim is to create a WBS which highlights a logical organization of products, parts and modules ( $\mathrm{Rad}, 2001)$. The next section discusses the role that a deliverable-oriented WBS can play in scope verification.

\subsection{The importance of deliverable-oriented WBS in scope verification}

Covey (1994) emphasizes the importance of having the end results in mind right from the beginning of a project. The deliverable-oriented approach in creating a WBS enforces this - the end result is project deliverables. According to Rad (2001) a deliverable-oriented WBS provides a road map to the definition of scope of work. It also provides a 'clear picture of what needs to be accomplished' (U.S.A Government Accountability Office, 2006:65). Furthermore, deliverables serve as a basis for creating a WBS ( $\mathrm{Rad}, 2001)$. Moreover, a deliverable-oriented WBS facilitates the sharing of information and serves as a tool for communication and project scope control ( $\operatorname{Rad} \&$ Cioffi, 2004). The process of scope verification involves establishing as to whether the developed scope does conform to the user requirements (Schach, 1996) - verifying scope against user requirements, as indicated by Figure 1 below. That is, verifying that the scope addresses all user requirements. Therefore, scope verification encompasses, in a way, requirements analysis. In the process of clarifying the project scope and establishing its completeness with the users, one would be able to find out if the product(s) that will be produced through the completion of project scope would meet user requirements (Rouse, 2012).

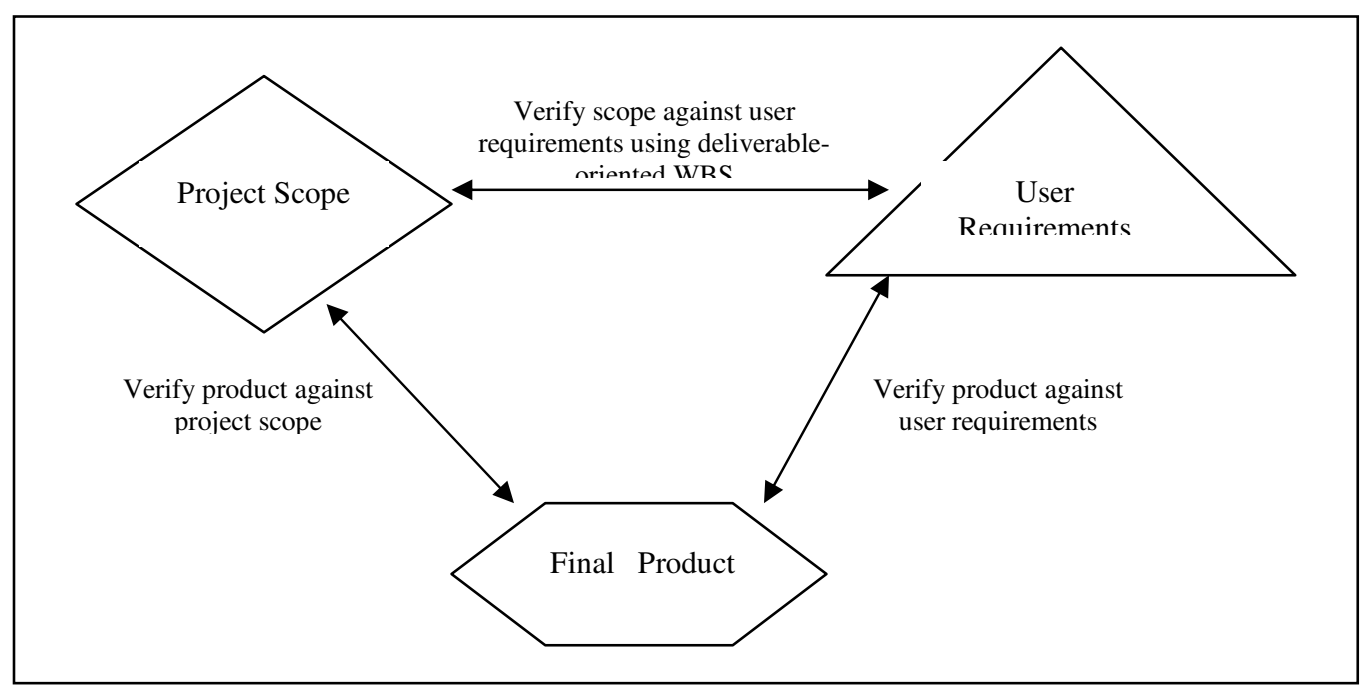

Figure 1 
A project scope which is contained in the project specification document (Schach, 1996) is a product of user requirements analysis process. Moreover, a deliverable-oriented WBS, which is the total project scope, focuses on what is to be produced in terms of project products. Therefore, such a structuring of work (scope) makes it easier for project managers to verify the scope against user requirements, because he/she knows what deliverables are expected in order to meet user requirements. The primary purpose of scope verification as it was pointed out above, is to establish the completeness of project scope in terms of user requirements. This would entail establishing as to whether all scope deliverables as outlined by the WBS are in fact complete in terms of user specification. This cross checking or reference using a deliverable-oriented WBS would also help detect misinterpretation of user requirements as well as omissions that might have occurred in the process of specification document development.

\subsection{Conclusion}

In the light of avoiding software project scope rework and promotion of better project scope control, project scope verification process is critical. Moreover, software scope verification is an important process in ensuring that the project team delivers exactly what the customer requested and minimizes project scope changes. A deliverable-oriented WBS provides project managers with a scope verification tool to ease the challenge of scope verification (Schwalbe, 2011). This paper has argued this assertion in the preceding sections.

\section{LIMITATIONS}

This paper has only presented a conceptual argument in as far as using a deliverable-oriented WBS for software project scope verification process, and therefore empirical evidence is needed to support the claim.

\section{FUTURE RESEARCH}

The practical usefulness and benefits of using a deliverable-oriented WBS as a software project scope verification tool need to tested and validated.

\section{REFERENCES}

[1] Brewer, J.L., \& Dittman, K.C. 2010. Methods of IT Project Management. USA: Pearson Prentice Hall

[2] Chua, D.K.H. \& Godinot, M. 2006. 'Use of a WBS Matrix to Improve Interface Management in Projects', Journal of Construction Engineering and Management, January 2006.

[3] Covey, S. 1994. First Things First. USA: Pearson Prentice Hall.

[4] Fuller, M.A., Valacich, J.S. \& George, J.F. 2008. Information Systems Project Management. USA: Pearson Prentice Hall.

[5] Malone, B.A. 2012. 'Work Breakdown Structure'. OPEN MIC.

[6] Rad, P.F. 2001. 'Advocating a Deliverable-Oriented Work Breakdown Structure', Cost Engineering, 41(12): 35-39

[7] Rad, P.F. \& Cioffi, D.F. 2004. 'Work and Resource Breakdown Structures for Formalized Bottom-Up Estimating', Cost Engineering, 46(2): 31-37

[8] Rouse, M. 2012. Requirements analysis (requirements engineering) [Online]. Search Software Quality. Available from: http://searchsoftwarequality.techtarget.com/definition/requirements-analysis [Accessed: 06 September 2012] 
[9] Schach, S.R. 1996. Classical and Object-Oriented Software Engineering. 3rd ed. USA: Irwin.

[10] Schwalbe, K. 2011. Information Technology Project Management. 6th ed. USA: Thomson Course Technology.

[11] U.S.A Government Accountability Office. 2006. Work Breakdown Structure - Chapter 8.

[12] Zhao, J.G. 2006. 'Significance of WBS in Contigency Modeling', AACE International Transactions.

\section{AUTHORS}

Robert Hans is a lecturer at Tshwane University of Technology (TUT), where he teaches project management as well as systems analysis and design subjects. He has worked for many years in the ICT industry before joining TUT three years ago. Robert has a master's degree in business leadership (MBL) from University of South Africa Graduate School of Business Leadership. He received a distinction for his research paper in his master's degree. He is currently studying for a doctoral degree with the University of South Africa. So far Robert has published two peer-reviewed journal papers and conference proceedings in project

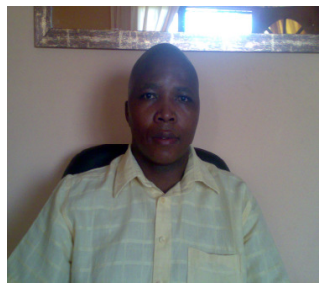
management. 